\title{
O Conceito de refração em Adorno: entre teoria estética e teoria do conhecimento
}

\author{
JESSICA DI CHIARA *
}

RESUmo Em sua Teoria Estética, Theodor W. Adorno, ao falar da relação entre arte e sociedade, apresenta e elabora a noção de "refração" tanto como um momento produtivo importante, quanto como o efeito característico da obra de arte moderna. A refração, forçada pelo caráter de aparência da arte, seria o que conferiria à obra o seu aspecto de liberdade e autonomia, mas também de não-comunicação com o mundo empírico. Se aceitarmos que, em termos físicos, a refração nada mais é que a mudança de direção de uma onda de luz que então deforma a imagem de um objeto, essa noção é valiosa para pensarmos que o que a arte estabelece é possivelmente uma nova relação de conhecimento com um objeto, a saber: o todo social. Nesse jogo de luzes, a obra de arte ilumina aspectos "obscuros" ou "negados" da vida social que servem de matéria para o crítico de arte desenvolver uma crítica da cultura. Se o ensaio é a forma contemporânea da apresentação do pensamento, como escreve Adorno em "O ensaio como forma", e se o ensaio fala, privilegiadamente, de objetos culturais pré-formados, ou seja, de obras de arte, fazendo confundir, assim, os limites entre "filosofia" e "crítica”, é porque ele põe em questão noções como as de conhecimento e verdade na História da Filosofia. Investigando as relações entre pensamento e materialidade na filosofia de Adorno do ponto de vista da forma, esta comunicação pretende estabelecer uma relação entre refração e reflexão, entre teoria estética e teoria do conhecimento, a partir da hipótese de que as obras de arte refratadas oferecem um modelo de conhecimento reflexivo que o ensaio guarda relação por ser inerente à ele pensar-se enquanto forma, enquanto crítica da linguagem.

em Filosofia

PALAVRAS-ChAVE Teoria estética; refração; Theodor W. Adorno; ensaio. 
"Poesia é linguagem em estado de crise"

Mallarmé

PARA um filósofo que entende a escrita como forma de morada em exílio, a decisão de retorno à pátria não deixou de ser uma escolha pela língua. No aforismo "Atrás do espelho", que abre a segunda parte de Minima Moralia (1951), por exemplo, Theodor W. Adorno escreve: "Para quem não tem mais pátria, é bem possível que o escrever se torne sua morada". Posteriormente, no texto “Sobre a pergunta: O que é alemão?", ensaio de 1965 que compõe seu último livro publicado em vida, Palavras e sinais: modelos críticos II (1969), ele retorna a essa questão e a justifica: “A resolução do retorno à Alemanha não foi motivada simplesmente por uma necessidade subjetiva - embora eu não a negue -, por saudades da terra [Heimweh].Também um fator objetivo se fazia presente: o idioma" ${ }^{2}$. A impossibilidade de continuar produzindo textos em inglês, motivo de retorno, e nos Estados Unidos - país onde passou a maior parte de seus anos de exílio (de 1938 a 1952) após uma breve temporada na Inglaterra - foi tomada após diversas tentativas de editores americanos "revisarem" seus textos porque neles a sintaxe não estava clara. ${ }^{3}$

1 ADORNO, Theodor W. Minima moralia: Reflexões a partir da vida danificada, p. 75. No original: "Wer keine Heimat merh hat, dem wird wohl gar das Schreiben zum Wohnen." A formulação que, a princípio, pode soar bastante heideggeriana pelo vocabulário, se distancia, porém, da proposta fenomenológica porque não há, nesse caso, uma ontologia que pensa o Ser morando na linguagem. Essa frase solicita, ao contrário, uma espécie de ética do escritor na prática da escrita, especificamente de uma escrita que se faz em exílio, dessa escrita que testemunha, então, uma situação particular e única daquele que pôde escrever esta frase.

2 ADORNO, Theodor W. Palavras e sinais: modelos críticos II, p. 133.

3 Cito, aqui, a passagem em que Adorno narra estes episódios, por ser bastante elucidativa: "Um editor, de resto também emigrado europeu, manifestou o desejo de publicar em inglês a parte principal da Philosophie der neuen Musik, da qual conhecia o manuscrito em alemão. Pediu-me o esboço da tradução. Quando o leu, achou que o livro que já conhecia era 'badly-organized'. (...) Alguns anos depois, o episódio repetiu-se, grotescamente ampliado. Eu havia proferido uma conferência para a associação psicanalítica de São Francisco, oferecendo sua publicação para a respectiva revista. Descobri, através das provas editoriais, que não se haviam contentado com a correção das falhas estilísticas que haviam escapado ao emigrante. O texto inteiro estava modificado até o irreconhecível, impossibilitando redescobrir a intenção de base. Ao meu amável protesto, recebi não menos 
Talvez seja significativo que um dos poetas que mais se rebelou contra a gramática e a sintaxe norte-americanas, e. e. cummings, anos antes, tenha sido recusado diversas vezes por editores no país. NO THANKS: assim cummings intitulou seu livro de poemas publicado em 1935. O título faz alusão às 14 respostas negativas que obtive dos editores aos quais submeteu seus originais ${ }^{4}$. Talvez - sem com isso querer abolir o espaço que os distingue - essas sejam dificuldades análogas entre o poeta e o filósofo.

Fazendo um uso não ortodoxo da tipografia, quebrando a linearidade da página e do verso, fragmentando a palavra, espacializando o poema, etc., a poética de cummings reúne uma série de recursos formais cuja proposta seria "liberar a ordem das palavras", segundo Augusto de Campos5. O último livro que publicou em vida, 95 Poems (1958) se inicia com um poema que experimenta e opera alguns desses procedimentos:

$\begin{array}{ll}\text { l(a } & \text { so } \\ \text { le } & (1 \\ \text { af } & \text { f } \\ \text { fa } & \text { o } \\ \text { II } & \text { 1)1 } \\ \text { s) } & \text { (ha } \\ \text { one } & \text { c } \\ \text { l } & \text { ai) } \\ \text { iness } & \text { itude }\end{array}$

delicadas e pesarosas explicações: a revista devia a sua reputação à sua prática de submeter todas as contribuições à tal 'editing', à tal redação. Ela operava no sentido da uniformidade; ainda estava em tempo de desistir da preferência. Desisti." (“Sobre a pergunta: O que é alemão?”. Op. Cit., p. 131-132).

4 Cf. a edição bilíngue, traduzida e introduzida por Augusto de Campos, Poem (a)s / E. E. Cummings. Campinas: Ed. Unicamp, 2011.

5 CAMPOS, Augusto de. “E. E. Cummings, sempre jovem”, p. 14. 
Composto apenas por uma palavra e uma frase, 20 letras e dois parênteses - solidão (uma folha cai), a fragmentação que cummings propõe neste poema é da ordem do mínimo: dissecando as palavras até restar menos que a sílaba, é com esse "mínimo arsenal" que ele projeta sobre nós uma densa imagem de solidão, movimento e delicadeza, nessa espécie de "haicai da folha-que-cai"'. Se Adorno, diferentemente de cummings, poeta do mínimo, escreve, por sua vez, extensamente - é muito comum que seus parágrafos ultrapassem páginas e páginas - ambos parecem se encontrar aqui pela situação comum de um exílio na linguagem pela escrita. Também podemos dizer que ambos, poeta e filósofo, nos lançam recorrentemente desafios pelo texto. Por exemplo: que leitura é solicitada por este poema de cummings? Parece que qualquer fala ou recitação são abolidas pela necessidade objetiva de o poema aparecer impresso, sendo, neste caso, a disjunção entre imagem e fala um procedimento formal do poema. No caso de Adorno, quantas vezes não se chegou ao senso comum da impossibilidade de se comentar seus textos pela dificuldade não apenas de seus conteúdos, mas sobretudo de se afastar de seu vocabulário, de sua sintaxe?7 Talvez as dificuldades de publicar que ambos experimentaram durante a vida se dêem não apenas por questões de experimentação formal, mas a disjunção que essas escritas fazem operar pode ser uma chave de leitura dessa "recusa" editorial (ou seja, daquilo que opera no limiar entre língua e mercado). Talvez seja essa disjunção que os comentadores apontem para a dificuldade do texto adorniano, como se nele fosse imprescindível a forma.

Haveria algo na arte que justamente desarticularia a linguagem? Mais especificamente na poesia que deslocaria a escrita? É possível pensar, no caso de Adorno, que a na-

6 CAMPOS, Augusto. “Intradução de Cummings", p. 38.

7 É notável que grandes críticos e professores, como Martin Jay, Marc Jimenez, José Guilherme Merquior, Márcio Seligmann-Silva e Rodrigo Duarte, que se dedicam ou dedicaram, cada um a seu modo, a comentar partes da obra adorniana, recorrentemente começam suas interpretações fazendo alusão a uma espécie de "pedido de desculpas” prévio ao leitor, pelo fato de eles mesmos, ao estarem comentando ou introduzindo o pensamento de Adorno correrem, ao mesmo tempo, o risco iminente de, a qualquer momento, se afastar da complexidade de seu pensamento pelo modo como ele o expressou em seus textos. Um “tipo de pensamento refratário à paráfrase”, dirá Martin Jay na introdução de seu livro As idéias de Adorno, ou "Escrever uma apresentação da obra de Adorno do ponto de vista do seu legado, e tendo em vista uma divulgação de seu pensamento, tem algo de paradoxal e até de irônico", como afirma Marc Jimenez em Para ler Adorno. 
tureza dessa dificuldade tem a ver com o modo de apresentação de seu pensamento porque, nele, teoria estética e teoria do conhecimento estariam entrelaçadas?

No ensaio "Palestra sobre lírica e sociedade" (1957), Adorno desenvolve uma leitura que pretende, na contramão de um modo específico (e hegemônico) de relacionar arte e sociedade, fazer com que "a referência ao social" não leve a crítica "para fora

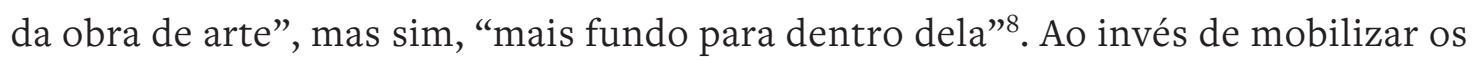
temas sociais dos poemas apenas para esquecê-los ou reduzi-los às teses sociológicas que se pretende "provar" num texto crítico, para ele o interessante é permanecer na obra e enxergar nela, a partir de dentro, a referência ao social como fundamento de sua qualidade, pois, é evidente para ele que o pensamento sobre a obra de arte está autorizado e comprometido a perguntar concretamente pelo teor social e a não se contentar com algo universal e abrangente. Assim, esse tipo de determinação pelo pensamento não é uma reflexão externa ou alheia à arte, mas antes uma "exigência de qualquer configuração linguística" . Além disso, continua Adorno:

Esse pensamento (...) não pode portanto ter em mira, sem mediação, a assim chamada posição social ou a inserção social dos interesses das obras ou até de seus autores. Tem de estabelecer, em vez disso, como o todo de uma sociedade, tomada como unidade em si mesma contraditória, aparece na obra de arte; mostrar em que a obra de arte lhe obedece e em que a ultrapassa. O procedimento tem de ser, confirme a linguagem da filosofia, imanente. (...) Aquela frase das Máximas e reflexões de Goethe, que diz que o que não entendes tu também não possuis, não vale somente para o relacionamento estético com obras de arte, vale também para a teoria estética: nada que não esteja nas obras, em sua forma específica, legítima a decisão quanto àquilo que seu teor, o que foi poeticamente condensado, representa em termos sociais. Determiná-lo requer, sem dúvida, não só o saber da obra de arte por dentro, como também o da sociedade fora dela. Mas esse saber só cria vínculos quando se redescobre no puro abandonar-se à própria coisa. ${ }^{10}$

8 ADORNO, Theodor W. Notas de Literatura I, p. 66.

9 Idem, p. 67.

10 Ibidem. [grifos meus]. 
Ou seja, neste ensaio, Adorno apresenta a tese de que, por exemplo, "uma corrente subterrânea coletiva"11 seria o fundamento de toda lírica, e, por isso mesmo, a noção de uma poesia lírica na modernidade carregaria consigo, apresentaria ela mesma intrinsecamente um momento de fratura: a dissonância, a disjunção, entre o sujeito - um "eu” que se apresenta - em oposição ao coletivo e ao social serviria, na verdade, para melhor expor o elemento social dos poemas. ("exatamente o não-social no poema lírico seria o seu elemento social”12). E isso só é passível de ser elaborado a partir de análises formais da obra. Analogamente, alguns anos depois, em sua grande e inacabada obra Teoria Estética, Adorno nos fornecerá modos de definir a relação entre arte e sociedade como, por exemplo, dizendo que "a arte é a antítese social da sociedade"13.

E aqui, vale dizer, quando enunciamos arte, em geral, na verdade estamos pensando a partir de uma concepção moderna de arte, que é a concepção que Adorno toma para si e sua filosofia como um modelo para o pensamento. A arte moderna, a arte do século XX, seria essa arte que torna necessário, a cada momento, colocar em questão a sua "natureza", refletir sobre a sua possibilidade de existência e permanência num mundo que, a princípio, pôs em risco e abaixo as noções de beleza, simetria e organização, por exemplo. Dessa arte, portanto, que perdeu uma ingenuidade e passa a pensar a sua forma. “Tornou-se manifesto que tudo o que diz respeito à arte deixou de ser evidente, tanto em si mesma como na sua relação ao todo, e até mesmo o seu direito à existência.”14 - assim começa a Teoria Estética.

No livro Para ler Adorno, Marc Jimenez afirma que a Teoria Estética “apresenta-se como uma série de fragmentos inacabados"15. Contudo, esse caráter fragmentário da obra pode ser compreendido em dois sentidos: por um lado, a obra mesma seria constituída por vários fragmentos - os parágrafos -, que seriam textos curtos cuja extensão não excederia duas ou três páginas; por outro, globalmente, a própria Teoria Estética pode ser considerada como um grande fragmento. Além disso, o caráter

\footnotetext{
11 Idem, p. 77.

12 Idem, p. 72.

13 ADORNO, Theodor W. Teoria Estética, p. 19.

14 Idem, p. 13.

15 JIMENEZ, Marc. Para ler Adorno, p. 13.
} 
fragmentário ainda pode ser atribuído (e o é mais comumente) a um outro motivo: como "resultado da presença da morte em uma obra que ainda não havia realizado a lei de sua forma"16 - por tratar-se de uma obra publicada postumamente e não revisada integralmente por Adorno. É verdade que há aí uma questão sempre aberta, não-resolvida, sobre a forma da grande obra de teoria estética do filósofo frankurtiano. No entanto, podemos duvidar se, ao fim e ao cabo, haveria ao final do texto alguma espécie de conclusão no sentido tradicional, visto que a Teoria Estética, de modo análogo às obras de arte de que ela se autoriza a falar, carregaria em sua composição formal a possibilidade alteração e desmembramento próprios à fragmentação, o que liberaria, dentro de uma interpretação adorniana da obra de arte, o seu conteúdo de verdade, assim como nas obras de arte. Ademais, a forma de apresentação “paratática” deste livro está intimamente ligada ao próprio conteúdo das ideias ali expressadas: condicionada objetivamente pela preocupação de não violentar, por uma estrutura pré-estabelecida, o que há de mais essencial no pensamento, Adorno afirma que "a unidade estética é a síntese não violenta dos elementos esparsos, que ela, no entanto, mantém tais quais são em sua divergência e contradição; daí ela ser apresentação da verdade" ${ }^{17}$. Sobre o processo de conformação de uma obra teórica dedicada à estética, em 24 de janeiro de 1968, Adorno analisa autorreflexivamente a forma de apresentação de suas ideias:

É interessante que, ao longo do meu trabalho, se tenham imposto a mim, a partir do conteúdo das ideias, certas consequências que deviam influir sobre a forma. Consequências que há muito já esperava, mas que ainda me surpreendem. Trata-se simplesmente do fato de que, a partir de meu postulado, nada é filosoficamente "primeiro". Segue-se que não se pode elaborar um sistema de argumentação segundo a progressão habitual, mas que se deve recompor o todo a partir de uma série de complexos parciais, tendo todos o mesmo peso, e sendo ordenados proporcionalmente de maneira concêntrica. A ideia provém da constelação destes, e não de uma “sucessão". (...) O livro só pode ser escrito de uma maneira, por assim dizer, concêntrica, sob a forma de partes equilibradas e paratáticas organizadas ao redor de um ponto central, a que elas dão expressão através desta constelação. ${ }^{18}$

16 Idem, p. 14.

17 ADORNO, Theodor W. apud JIMENEZ, Marc. Para ler Adorno, p. 14.

18 Idem, p. 16. 
Não é impossível pensarmos que essa forma de apresentação paratática de seus escritos reforce ou pense uma forma aporética da obra de arte. Tudo se passa como se a Teoria Estética procurasse evitar a enunciação afirmativa e categórica das coisas que ela tão frequentemente denuncia nas obras de arte. Assim é possível pensar neste livro, antes de tudo, como uma denúncia, sem, com isso, cair no erro de propor soluções a um problema que Adorno sabia não as comportar. A aporia aparece, então, no projeto de uma obra teórica, na qual o pensamento filosófico atesta, por sua presença, que lhe é impossível renunciar às tentações de resolver o insolúvel.

Direcionando nosso interesse para as relações entre a forma de apresentação da obra de arte e a forma de apresentação do pensamento para, com isso, indiretamente abordarmos a relação entre arte e sociedade, na Teoria Estética, ao falar dessa relação, Adorno apresenta e elabora a noção de refração (Brechung) tanto como um momento produtivo importante, quanto como o efeito característico da obra de arte moderna. A refração, forçada pelo caráter de aparência da arte, seria o que conferiria à obra o seu aspecto de liberdade e autonomia, mas também de não-comunicação com o mundo empírico (com o mundo cotidiano, tal como percebemos), posto que as obras de arte são ao mesmo tempo cópias desse mundo empírico e algo diverso dele. Na medida em que fornecem ao mundo ou à empiria, enquanto artefatos e, por isso, enquanto produtos de um trabalho social, o que lhe é recusado (alguma liberdade, por exemplo) renegam essa mesma empiria da qual retiram o seu conteúdo. É nesse sentido de pensar uma unidade em si mesma contraditória que Adorno dirá, sobre a participação da arte na sociedade que: “a comunicação das obras de arte com o exterior, com o mundo perante o qual elas se fecham, feliz ou infelizmente, leva-se ao cabo através da não-comunicação; eis precisamente porque elas se revelam como refratadas". ${ }^{19}$ É pela arte se opor à empiria através do momento da forma que a forma pode ser pensada como um modo de refração ou o modo como a refração se sedimenta num determinado objeto, já que o que seria refratado na obra de arte seria seu conteúdo, o todo social, e não podemos esquecer da célebre frase contida na Teoria Estética: "forma é conteúdo sedimentado" 20 .

19 ADORNO, Theodor W. Teoria Estética, p. 17.

20 Idem, p. 166. 
Se o ensaio é a forma contemporânea da apresentação do pensamento, como escreve Adorno em "O ensaio como forma” (1958), e se o ensaio fala, privilegiadamente, de objetos culturais pré-formados, ou seja, de obras de arte, fazendo confundir, assim, os limites entre "filosofia" e “crítica”, é porque ele põe em questão noções como as de conhecimento e verdade na História da Filosofia. Pois nesse jogo de luzes (ou de um outro esclarecimento), a obra de arte ilumina aspectos “obscuros” ou "negados” da vida social que servem de matéria para o crítico de arte desenvolver uma crítica da cultura. Se aceitarmos que, em termos físicos, a refração é a mudança de direção de uma onda de luz que, dependendo do meio onde se projeta, ou deforma a imagem de um objeto (como na água, por exemplo) ou revela as várias segmentações que constituem a coisa, numa espécie de dissecação do objeto (como num prisma, por exemplo, a luz branca mostra seus vários outros espectros), essa noção é valiosa para pensarmos que o que a arte estabelece é possivelmente uma nova relação de conhecimento, a cada vez, com um objeto mais amplo, a saber: o todo social (como uma estrutura monadologica). Investigando as relações entre pensamento e materialidade na filosofia de Adorno do ponto de vista da forma, este trabalho pretendeu estabelecer uma relação entre refração e reflexão, entre teoria estética e teoria do conhecimento, a partir da hipótese de que as obras de arte refratadas oferecem um modelo de conhecimento reflexivo que o ensaio guarda relação por ser inerente à ele pensar-se enquanto forma, enquanto crítica da linguagem. 


\section{BIBLIOGRAFIA}

ADORNO, Theodor W. Minima moralia: Reflexões a partir da vida danificada. $2^{\mathrm{a}}$ edição. Trad. Luiz E. Bicca. São Paulo: Ática, 1993.

Notas de Literatura I. Trad. Jorge de Almeida. São Paulo: Editora 34, 2003. “Sobre a pergunta: O que é alemão” In: Palavras e sinais: modelos críticos II. Petrópolis: Ed. Vozes, 1995.

CAMPOS, Augusto de. “E. E. Cummings, sempre jovem” In: Poem (a)s/e.e. Cummings. $2^{\text {a }}$ ed. revista e ampliada. Trad. Augusto de Campos. Campinas: Ed. Unicamp, 2011. “Intradução de Cummings" In: Poem (a)s / e. e. Cummings. $2^{\text {a }}$ ed. revista e ampliada. Trad. Augusto de Campos. Campinas: Ed. Unicamp, 2011.

JIMENEZ, Marc. Para ler Adorno. Trad. Roberto Ventura. Rio de Janeiro: Ed. F. Alves, 1977. 